\title{
|jilj 吸出症:
}

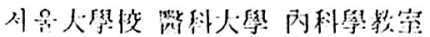

\section{康晰榮}

\section{Paragonimiasis Westermani}

\author{
Suck Young Kang, M.D., Ph.D. \\ Department of Internal Medicine, College of Medicine \\ Seoul National University
}

\section{序言}

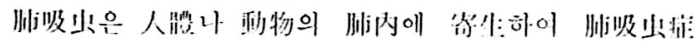

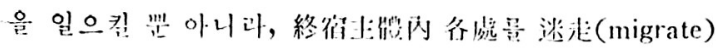

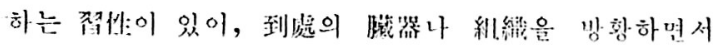

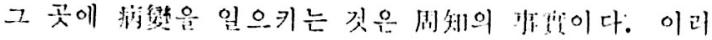

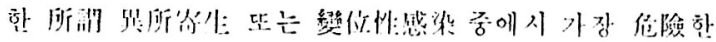

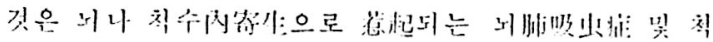

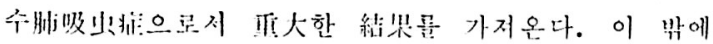

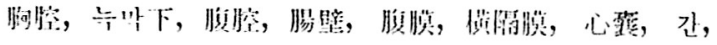

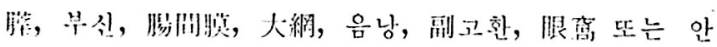

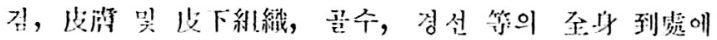

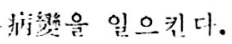

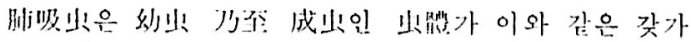
기 곳에 빙소류 形成한다는 것이 잘 알려저 있는테, 河

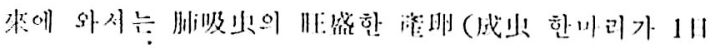
$9,530 \pm 1,300 \sim 18,383 \pm 4,20$ ) 으로 인한, 그 桨多한 出

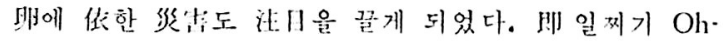
tani(大行), Taniguchi(谷口), Katsurada (H:m), Tana-

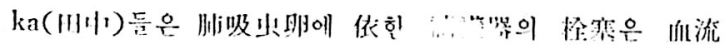
로 移行한다고 하있고, Nakayama(1, il)는 비증율 闬

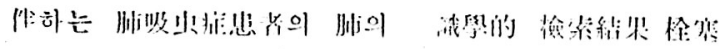

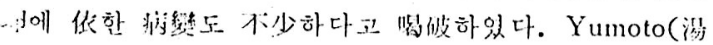
소)는 1943作 极吸怒染犬의 심장, 대니, 소네, 堅에 다

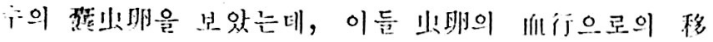

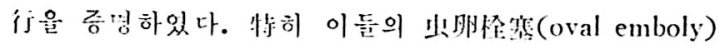

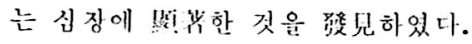

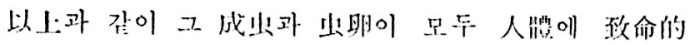

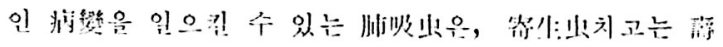

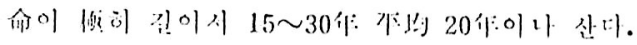

\section{地理的 分布}

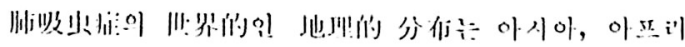

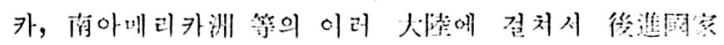

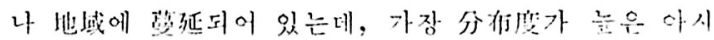

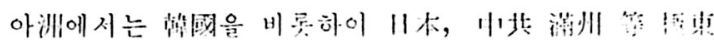

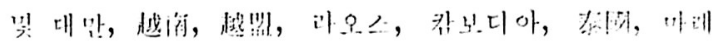

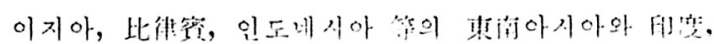

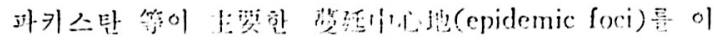
루고 있다.

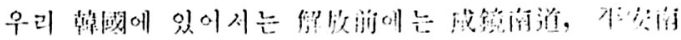

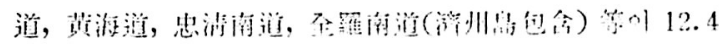

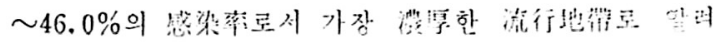

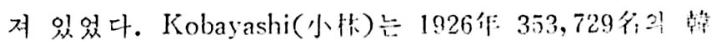

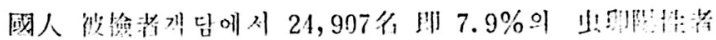

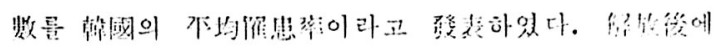

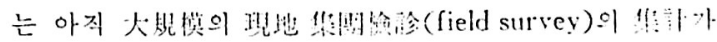

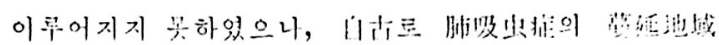

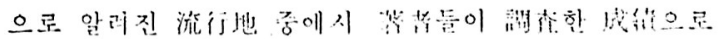

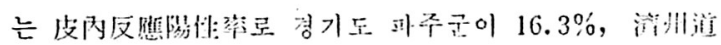

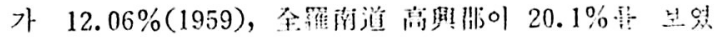

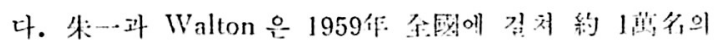

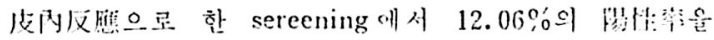
被终하고. 있다.

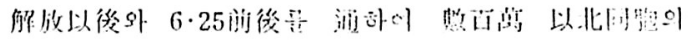

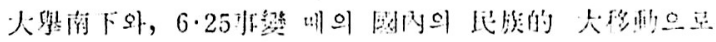

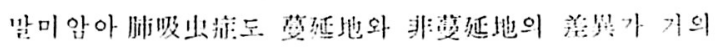

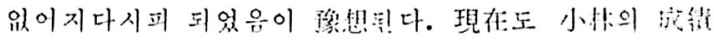

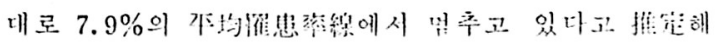

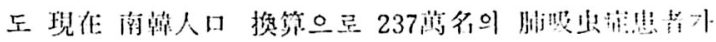
있는 셈이 단다.

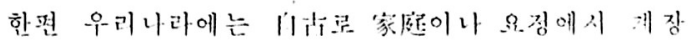

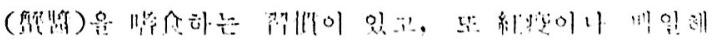

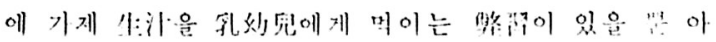

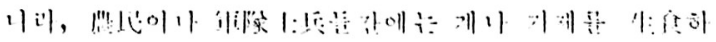

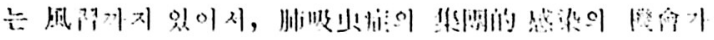




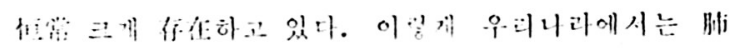

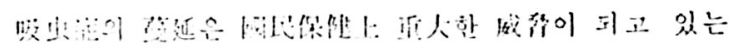
궁의.

\section{病因 吕病理}

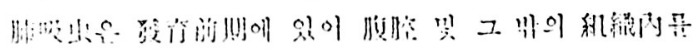

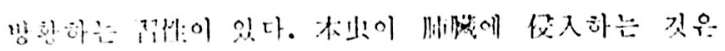

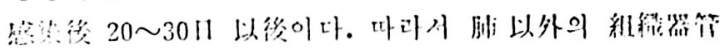

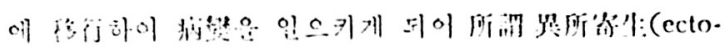

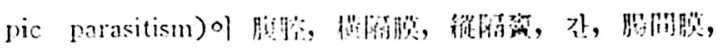

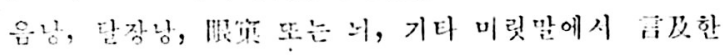

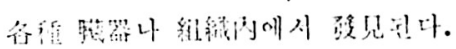

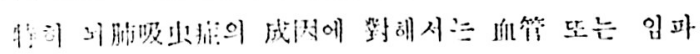

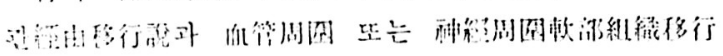

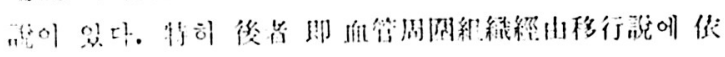

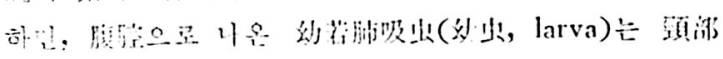

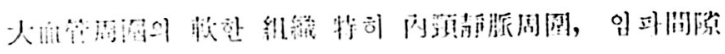

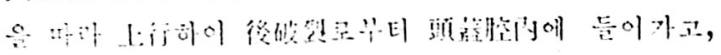

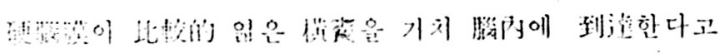

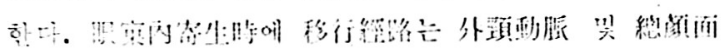

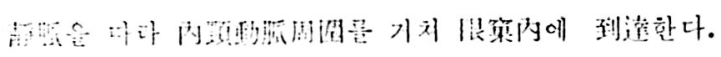

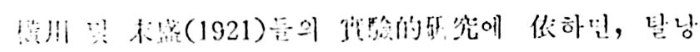

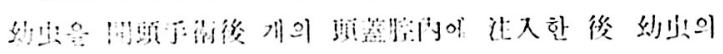

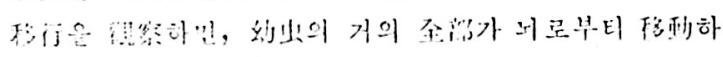

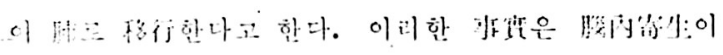

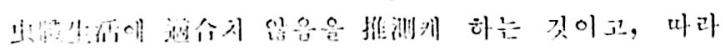

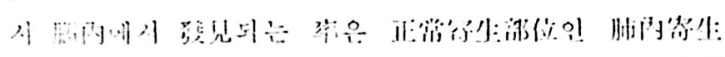

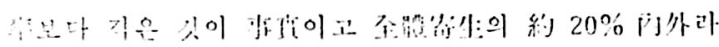

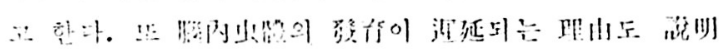

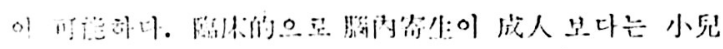

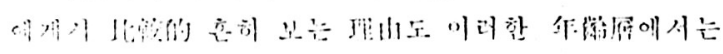

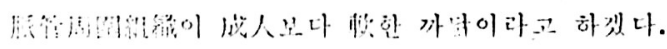

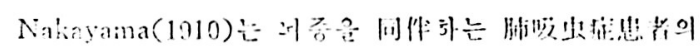

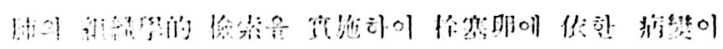

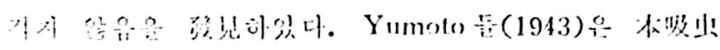

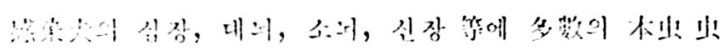

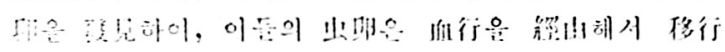

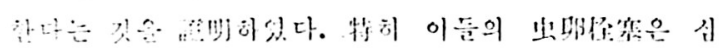

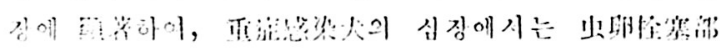

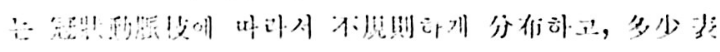

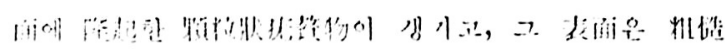

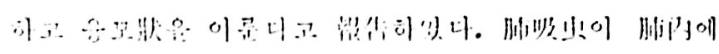

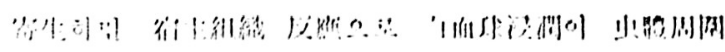

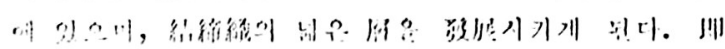

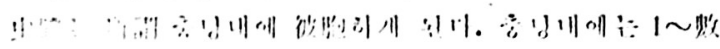

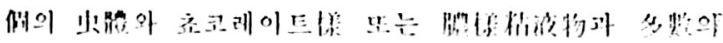

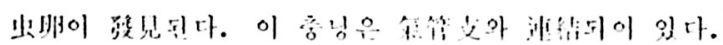

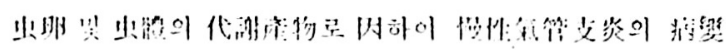

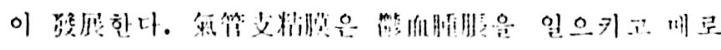

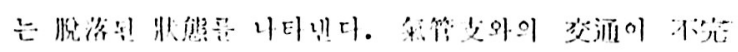

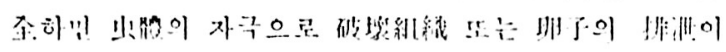

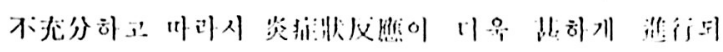

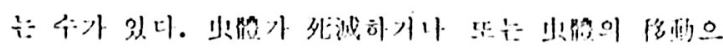

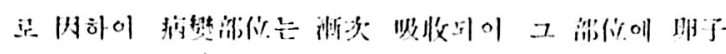

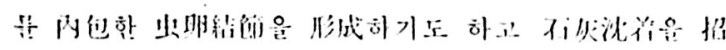

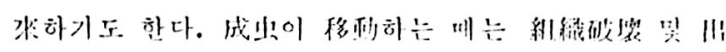

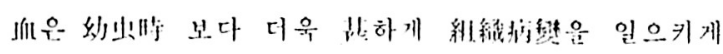
딘 다.

\section{症狀}

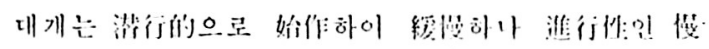

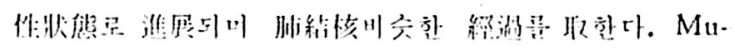

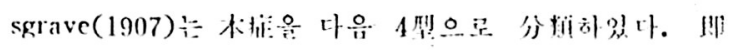

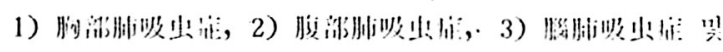

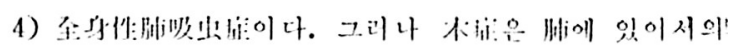

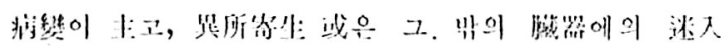

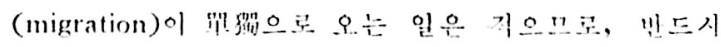

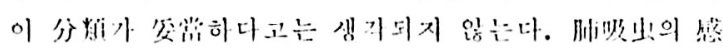

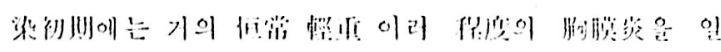

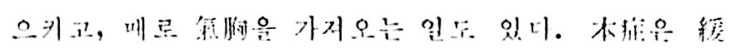

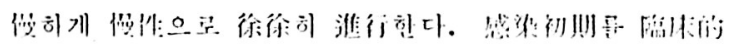

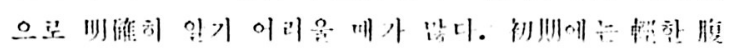

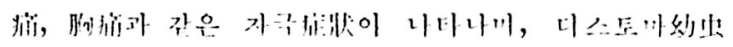

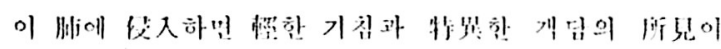

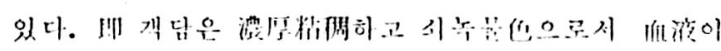

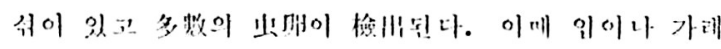

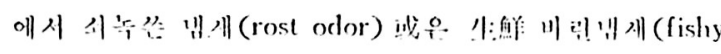

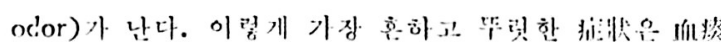
임 깃이다. 년

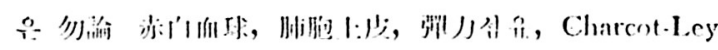

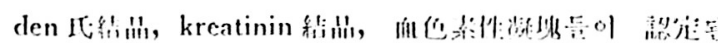

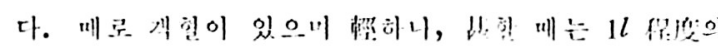

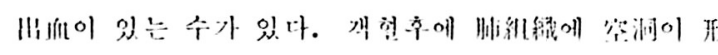

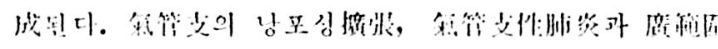

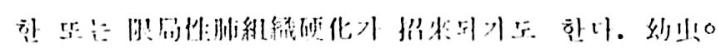

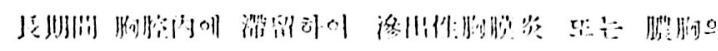

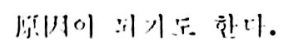

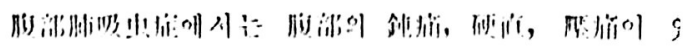

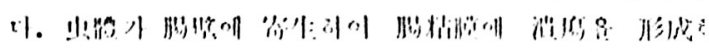

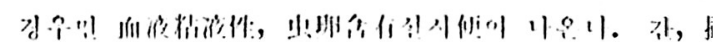




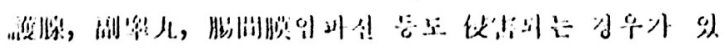

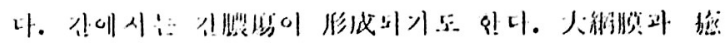

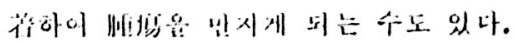

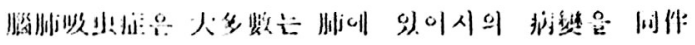

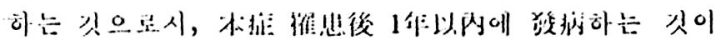

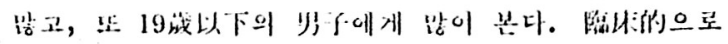

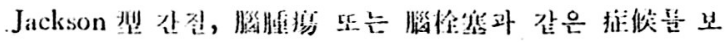

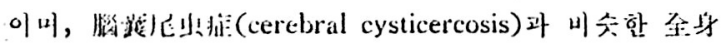

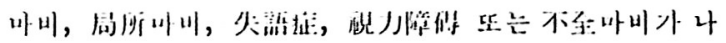

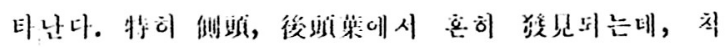

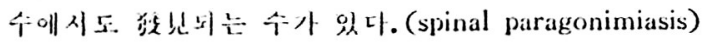

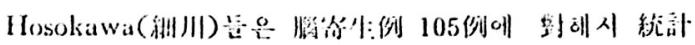

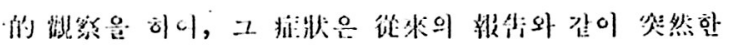

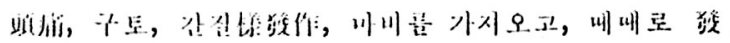

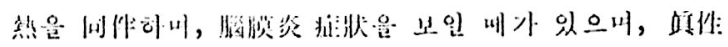

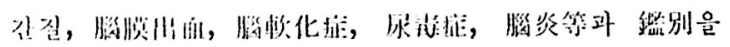

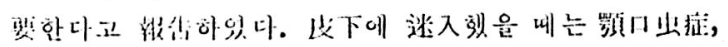

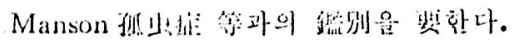

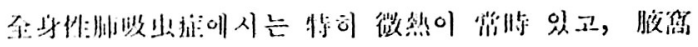

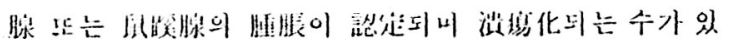

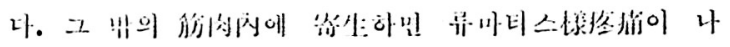

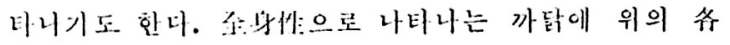

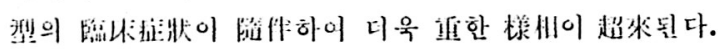

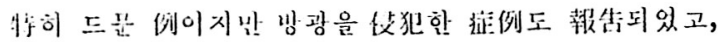

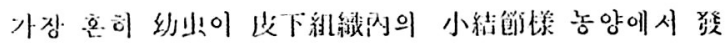
년된다.

\section{診斷}

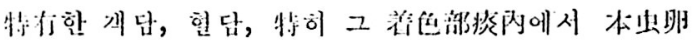

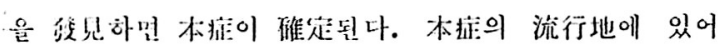

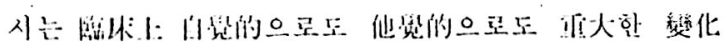
가 댒고, 때때로 만한 기침이 있으며 粘稀한 불엿(水

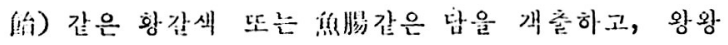

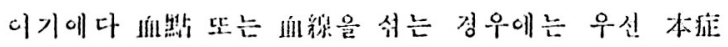

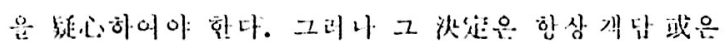

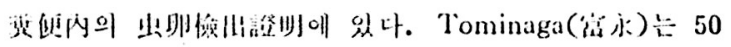

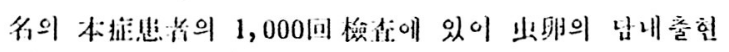

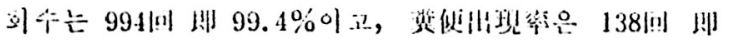

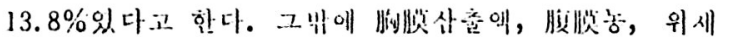

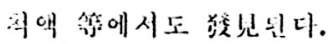

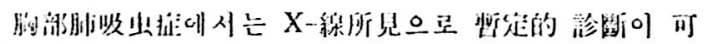

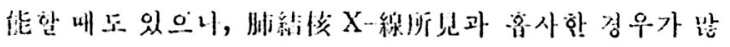

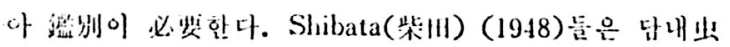

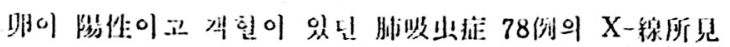

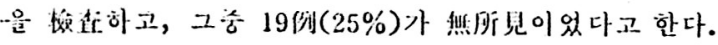

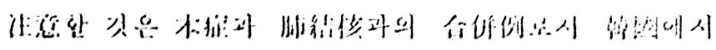

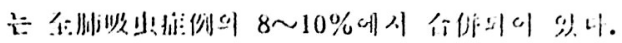

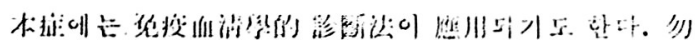

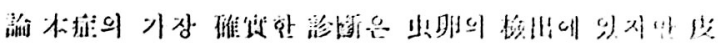

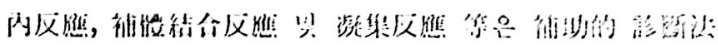

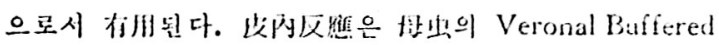
Saline(V.B.S.)扰原을 值用하그 있다. 이치한

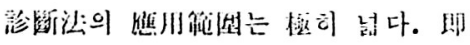

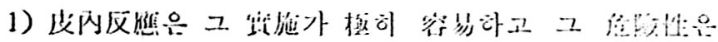

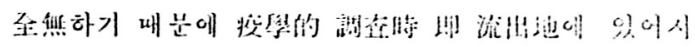

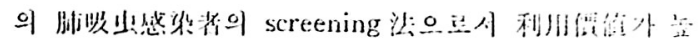
다.

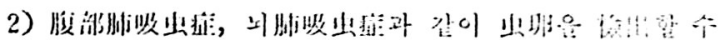

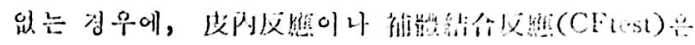
도운이 된다.

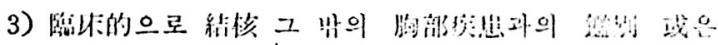

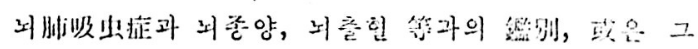

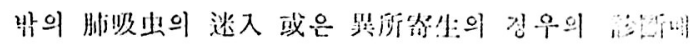

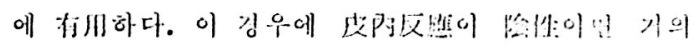

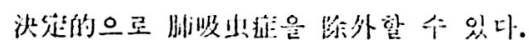

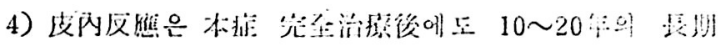

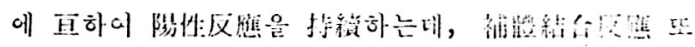

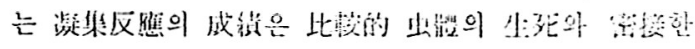

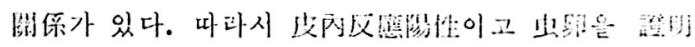

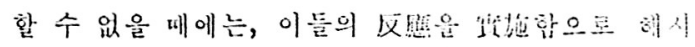

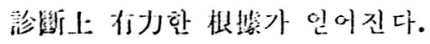

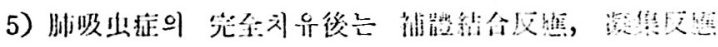

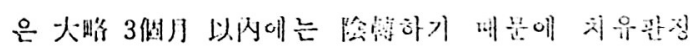
에 不凩하다.

\section{治 療}

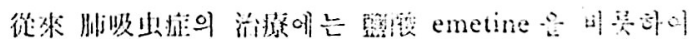
antimon 例, 인산 chloroquine, atabrine(quinacine),

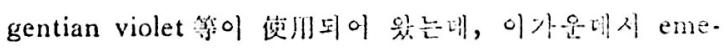

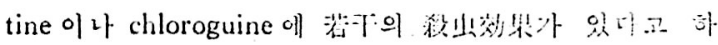

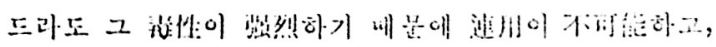

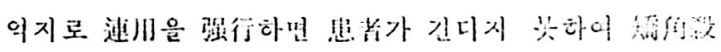

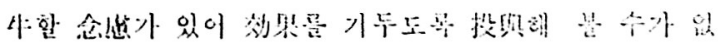

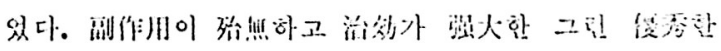

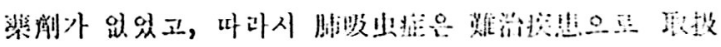
되어 왔었다. 그러던충 1961年에 이르러서 우리릐 벵

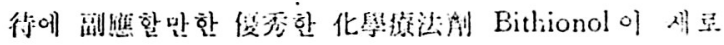
登增 6 한 것이다.

Bithionol 은 化孚名이 2,2'-thiobis( 4 , 6-dichlorophenol)

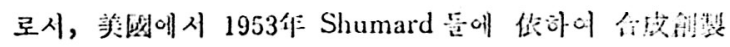




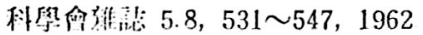

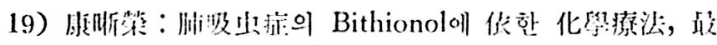

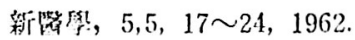

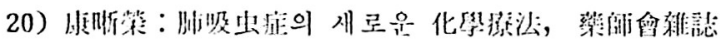
$3,8,51 \sim 55,1962$.

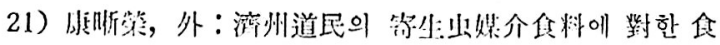

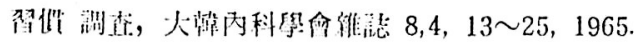

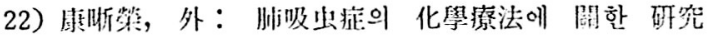

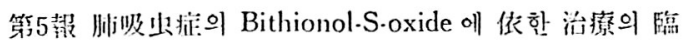
本的觀察，기 생 훙학잡지, $2,2,18,1964$.

23）庶哳第，外：肺吸出症의 化學療法에 閶한 破究, 第

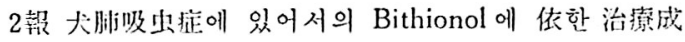

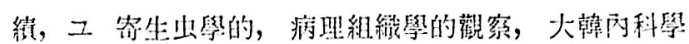
會雍誌，2，7,3,7 16, 1964. 